\title{
Recusas de borrifação de imóveis e ocorrência de casos de leishmaniose visceral na Regional Noroeste de Belo Horizonte
}

\author{
[Refusal of spraying of buildings and the occurrence of cases of visceral leishmaniasis in North West \\ region of Belo Horizonte, Brazil] \\ F.C. Santana Filho ${ }^{1}$, J.A. Silva' , D.F. Magalhães ${ }^{2}$, J.N.C. Meneses ${ }^{2}$, J.P.A. Haddad ${ }^{2}$, \\ M.H.F. Morais ${ }^{3}$, V.G. Almeida ${ }^{3}$ \\ ${ }^{1}$ Aluno de pós-graduação - Escola de Veterinária - Universidade Federal de Minas Gerais - Belo Horizonte, MG
${ }^{2}$ Escola de Veterinária - Universidade Federal de Minas Gerais - Belo Horizonte, MG
${ }^{3}$ Gerência de Controle de Zoonoses da Regional Noroeste - Prefeitura de Belo Horizonte, MG
}

RESUMO

Os objetivos desta pesquisa foram caracterizar as recusas por parte da população em permitir a borrifação de seus imóveis, em quatro regiões de Belo Horizonte, no período de 2006 a 2008, e relacionar estas recusas com o surgimento de casos de leishmaniose visceral, no mesmo local e período. Utilizaram-se as localizações onde se encontraram 27 casos humanos de leishmaniose visceral obtidos do SINAN, todos referentes a quatro áreas de abrangência da região noroeste de Belo Horizonte, no período de 2006 a 2008. De um total de 33.579 residências visitadas pelo controle químico vetorial, $9636(28,70 \%)$ aceitaram a borrifação interna e a externa do domicílio, $20741(61,77 \%)$ concordaram com a borrifação apenas do peridomicílio, $141(0,42 \%)$ aceitaram apenas a borrifação do intradomicílio, $909(2,70 \%)$ se encontraram fechadas no momento da borrifação e $2152(6,41 \%)$ recusaram qualquer tipo de borrifação no imóvel. Na maioria das residências, o controle químico foi permitido apenas no peridomicílio. A diferença entre o perfil de recusas dos quarteirões contidos em uma área de 200 metros ao redor de um caso humano de leishmaniose visceral e o mesmo perfil dos quarteirões fora desta área foi significativa $(\mathrm{P}<0,05)$ em sete $(25,92 \%)$ dos 27 casos da doença.

Palavras-chave: recusa de participação, controle de vetores, leishmaniose visceral

\begin{abstract}
The purpose of this study was to characterize the population's refusal to allow their houses to be sprayed in four regions of Belo Horizonte, in the period from 2006 to 2008, and relate these denials with the emergence of cases of visceral leishmaniasis in the same location and time. We used the location of 27 human cases of visceral leishmaniasis obtained from SINAN, all data from four regions in the West Region of the city of Belo Horizonte, from 2006 to 2008. Of a total of 33,579 houses visited by the chemical vector control, 9636 (28.70\%) accepted spraying inside and outside the home, 20741 (61.77\%) agreed with spraying only the areas surrounding the property, $141(0.42 \%)$ agreed only to spray indoors, $909(2.70 \%)$ were found closed at the time of spraying, and $2152(6.41 \%)$ refused any kind of spray at house. A chemical control vector was allowed only in surrounding areas of most of the houses studied. The difference between the profile of denials of the blocks contained in an area of 200 meters around a human case of $V L$, with the same profile of the blocks out of this area was significant $(P<0,05)$ in 07 $(25,92 \%)$ of 27 cases of the disease.
\end{abstract}

Keywords: refusal to participate, vector control, visceral leishmaniasis

Recebido em 2 de junho de 2011

Aceito em 9 de abril de 2012

E-mail: fernandocsf@gmail.com 


\section{INTRODUÇÃO}

A leishmaniose visceral é uma zoonose, causada por protozoários do gênero Leishmania, que pode levar à morte na ausência de tratamento. A doença era restrita às zonas rurais, mas tem apresentado, nos últimos anos, maior presença em grandes centros urbanos devido à migração de pessoas oriundas de áreas endêmicas, ao empobrecimento e ao baixo padrão de qualidade de vida em algumas áreas urbanas, além do aumento de cães infectados e da maior adaptação do inseto vetor aos ambientes peri e intradomiciliares (Desjeux, 2001; Barata et al., 2005; Rangel e Vilela, 2008).

O principal vetor da leishmaniose visceral no Novo Mundo é o Lutzomyia longipalpis. Este flebotomíneo se infecta ao sugar o sangue de animais contaminados pela doença (geralmente o cão, o principal reservatório da doença no ambiente urbano), podendo transmiti-la ao realizar novamente o repasto sanguíneo em outro animal, inclusive no homem. O ciclo biológico da leishmaniose visceral é, portanto, complexo e envolve vários fatores do ambiente, do agente e do hospedeiro, tornando o controle da doença caro e laborioso, principalmente nas áreas urbanas e periurbanas (Marzochi et al., 1985).

O Programa de Controle da Leishmaniose Visceral do Ministério da Saúde tem como objetivos a diminuição dos níveis de transmissão da doença e a redução da taxa de letalidade. A Prefeitura de Belo Horizonte tem realizado ações de controle da doença que incluem o diagnóstico precoce e o tratamento dos casos humanos, inquérito canino e eutanásia dos cães soropositivos, controle entomológico com a borrifação de residências e promoção de programas de educação em saúde. O controle da população do inseto vetor é baseado na aplicação de inseticida intra e peridomiciliar e no manejo ambiental. $\mathrm{O}$ inseticida utilizado é um piretroide (alfacipermetrina), borrifado em toda a extensão das paredes do intradomicílio e do peridomicílio das residências selecionadas após avaliação das áreas de risco para a doença, conforme o Programa de Controle da Leishmaniose Visceral (Brasil, 2006).

Assim como as outras práticas do programa, o controle químico vetorial enfrenta muitas dificuldades e limitações, pois é caro, de difícil execução e requer uma grande cooperação dos proprietários das residências. Tais limitações favorecem para que o número de casos humanos e caninos da enfermidade ainda se mantenha elevado (Gontijo e Melo, 2004).

Uma das dificuldades, citada em alguns trabalhos, é a recusa da população em permitir a borrifação de seus imóveis (Dias, 1998; Camargo-Neves, 2005; Tauil, 2006; Silva et al., 2007). A execução do controle químico vetorial nas residências é realizada mediante o consentimento do proprietário, o que muitas vezes não acontece. Nesta situação, resta ao poder público orientar o morador quanto às práticas de manejo ambiental contra a leishmaniose visceral e os riscos advindos da não borrifação do imóvel. Muitas vezes o motivo para a recusa é o desconhecimento do morador acerca da leishmaniose visceral. A educação em saúde seria, portanto, atividade essencial para solucionar este problema e aumentar a eficiência das ações de controle da doença (Borges et al., 2008; Magalhães et al., 2009).

Este trabalho teve como objetivos conhecer o perfil das recusas da população ao controle químico vetorial em quatro áreas de abrangência da regional noroeste de Belo Horizonte, entre os anos de 2006 a 2008, e relacionar estas recusas de borrifação de residências com a ocorrência de casos humanos de leishmaniose visceral. Deste modo, deseja-se contribuir para a melhoria de um instrumento de controle da doença, tanto na população canina como na humana, oferecendo respaldo científico para o serviço de saúde pública frente à recusa dos moradores às suas ações.

\section{MATERIAL E MÉTODOS}

O município de Belo Horizonte está localizado na região central de Minas Gerais, na bacia do rio São Francisco. Possui um clima predominantemente tropical, (com temperatura média anual em torno de $21^{\circ} \mathrm{C}$ ) e uma altitude média de 852 metros. A cidade possui uma população de 2.412.937 habitantes, com PIB per capita de R\$13.636 (IBGE, 2007), em uma área de aproximadamente $332 \mathrm{~km}^{2}$, delimitada pelas latitudes $19^{\circ} 46^{\prime} 35^{\prime \prime}$ e $20^{\circ} 06^{\prime} 34^{\prime \prime}$ ao sul do equador e pelas longitudes $43^{\circ} 51^{\prime} 27^{\prime \prime}$ e $44^{\circ} 03^{\prime}$ 47 " a oeste de Greenwich. 
Para fins administrativos e de planejamento, o município de Belo Horizonte é dividido em nove Administrações Regionais (Barreiro, Centro-Sul, Leste, Nordeste, Noroeste, Norte, Oeste, Pampulha e Venda Nova). Na Regional Noroeste, as áreas de abrangência do Pindorama, Santos Anjos, Bom Jesus e Dom Bosco foram as escolhidas por possuírem maior número de casos humanos da doença nos anos de 2006 a 2008 e por terem sido as únicas a receberem o controle químico vetorial feito de forma sistemática ao longo destes três anos, razão esta que explica a escolha do período utilizado nesta pesquisa. Além disso, são áreas que apresentam historicamente muitas recusas dos proprietários em permitir o trabalho dos agentes do serviço de saúde em seus domicílios.

O estudo foi dividido em três etapas: 1) obtenção, seleção e localização dos dados referentes aos trabalhos de controle químico vetorial e casos humanos de leishmaniose visceral; 2) visualização da distribuição dos dados em mapas temáticos, por meio da localização das recusas da população em permitir os trabalhos de borrifação, e dos casos humanos de leishmaniose visceral; 3) análise da hipótese por meio do teste estatístico $\mathrm{T}$ de Student (Sampaio, 1998).

Os dados referentes ao trabalho de controle químico vetorial foram obtidos na Gerência Distrital de Controle de Zoonoses da Regional Noroeste, a partir de boletins manuscritos preenchidos pelos agentes de combate a endemias que realizam o trabalho de controle da leishmaniose visceral. Os dados de casos humanos de leishmaniose visceral foram obtidos por meio do Sistema de Informação de Agravos de Notificação (SINAN) referentes às quatro áreas de abrangência utilizadas no estudo, nos anos de 2006 a 2008.

Neste período, foi notificado e confirmado à Secretaria Municipal de Saúde um total de 31 casos humanos de leishmaniose visceral, nas quatro áreas de abrangência do estudo. Neste mesmo período e região, foi visitado pelos agentes de combate a endemias um total de 33.579 residências para controle químico vetorial.

As residências trabalhadas foram divididas em três grupos, de acordo com o local borrifado: borrifação total (residências onde se borrifaram o peridomicílio e o intradomicílio), borrifação interna (residências onde a borrifação foi recusada no peridomicílio e permitida apenas no intradomicílio) e borrifação externa (residências onde a borrifação foi recusada no intradomicílio e permitida apenas no peridomicílio).

As residências não trabalhadas, por sua vez, foram divididas em dois grupos, de acordo com o motivo da não realização do trabalho: imóvel fechado (residência onde não se encontrava nenhum morador no horário agendado para o controle químico vetorial) e imóvel recusado (residência onde a borrifação não foi permitida tanto no intradomicílio como no peridomicílio).

Para a confecção dos mapas, foi utilizado o software TerraView (Terraview, 2008), de domínio público, por meio do qual todos os endereços (controle químico vetorial e casos humanos de leishmaniose visceral) foram georreferenciados pontualmente, gerando os mapas das quatro áreas de abrangência do estudo.

Cada um dos endereços referentes às recusas recebeu um escore de risco, unitário e gradual, de acordo com o tipo de recusa. Esta pontuação foi baseada na proteção que o controle químico vetorial confere às residências. Quanto maior a recusa pela borrifação, maior a pontuação recebida.

Para facilitar a análise da distribuição dos diferentes tipos de recusa nos mapas, esta variável foi visualizada agrupada em quarteirões. Cada quarteirão, portanto, recebeu uma pontuação, resultado da média ponderada do escore de todas as residências contidas neste quarteirão. Posteriormente, cada quarteirão recebeu uma cor de acordo com esta pontuação, sendo assim estabelecida: cinza para os quarteirões sem informação (onde nenhuma residência foi visitada para controle químico censitário, ou devido ao fato de se perderem informações); azul para quarteirões com pontuação até 1,40; verde para quarteirões com pontuação entre 1,40 e 2,10; amarela para pontuação entre 2,10 e 2,80 ; e vermelha para quarteirões com pontuação acima de 2,80.

A associação das áreas de recusas da borrifação com os casos humanos de leishmaniose visceral 
foi realizada observando-se os arredores de cada residência acometida pela doença. Em uma área de 200 metros ao redor de cada caso da doença, verificou-se a média da pontuação dos quarteirões contidos dentro desta área e comparou-se com a média da pontuação dos quarteirões localizados fora desta mesma área. A distância de 200 metros foi utilizada por se tratar da distância média de voo do inseto vetor da leishmaniose visceral (Alexander e Young, 1992).

O teste T de Student foi utilizado para se avaliar a variância destas médias e a significância das diferenças. As diferenças foram consideradas estatisticamente significativas quando a probabilidade de erro se mostrou menor que 0,05 , ou seja, o escore de risco dentro da área de 200 metros ao redor do caso foi maior que o escore de risco fora desta área.

\section{RESULTADOS E DISCUSSÃO}

Dos 33.579 imóveis visitados pelo controle químico vetorial, no período e na área de estudo, foram borrifados 30.518 (90,88\%), e não borrifados $3.061(9,12 \%)$.

Entre os imóveis borrifados, 141 (0,46\%) receberam a borrifação somente do intradomicílio, $20.741(67,96 \%)$ receberam a borrifação somente do peridomicílio e 9.636 $(31,58 \%)$ imóveis foram borrifados nos dois locais.

Do total de imóveis não borrifados, 909 $(29,70 \%)$ não o foram por estarem fechados no momento agendado para a borrifação e 2.152 $(70,30 \%)$ tiveram como motivo a recusa do proprietário. Todos os dados referentes ao controle químico vetorial se encontram nas Fig. 1,2 e 3 .

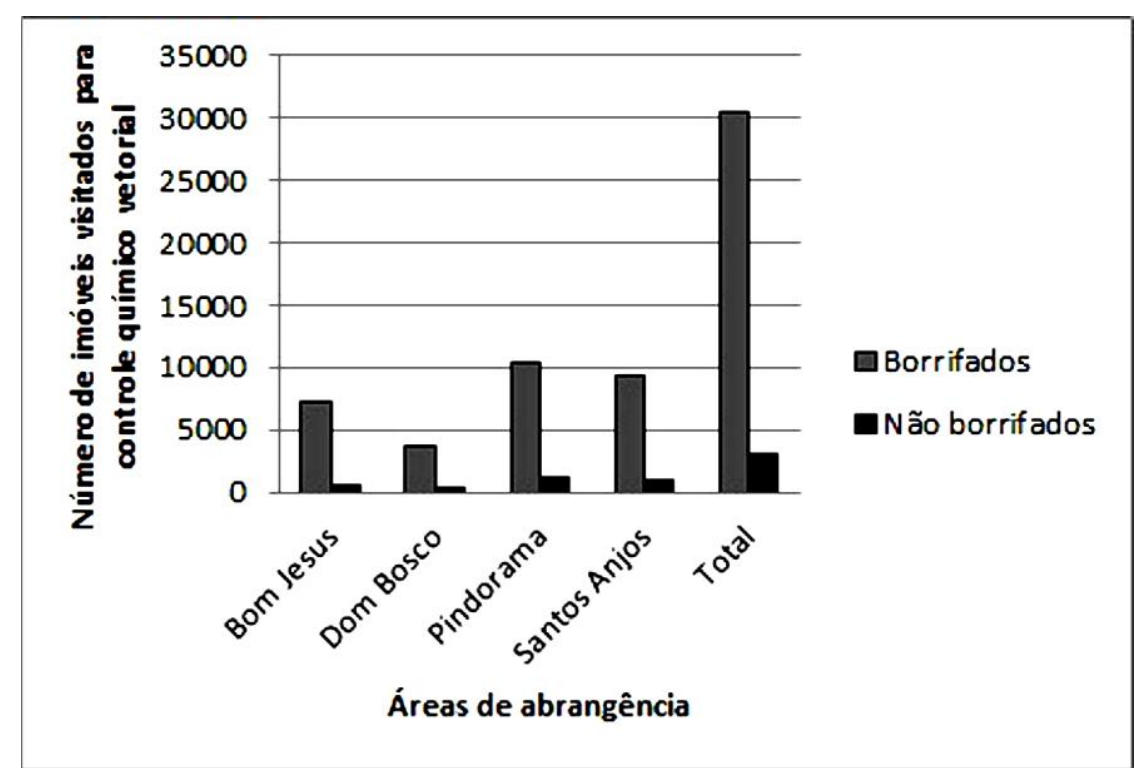

Figura 1. Número de imóveis visitados para controle químico vetorial, em quatro áreas de abrangência da Regional Noroeste de Belo Horizonte, de 2006 a 2008.

Observa-se que, mesmo com um décimo dos imóveis visitados não sendo borrifados, o Pindorama foi a área de abrangência com maior número de residências protegidas, seguido pelo Santos Anjos, Bom Jesus e Dom Bosco. A proporção de imóveis não borrifados $(9,12 \%)$ evidencia que o controle químico vetorial precisa atingir uma melhor aceitação pela população, conforme ressaltaram Dias (1998) e Tauil (2006), dada a importância da leishmaniose visceral no contexto da saúde pública. 


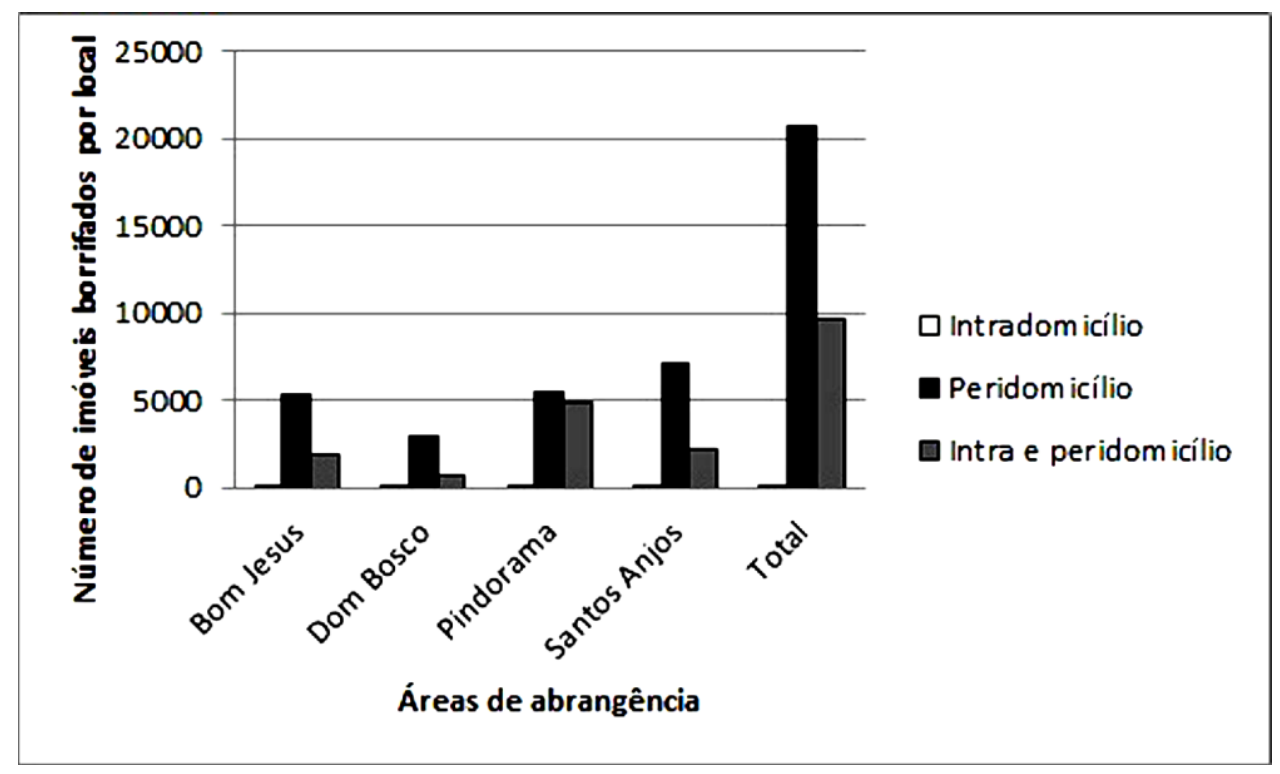

Figura 2. Número de imóveis borrifados por local, em quatro áreas de abrangência da Regional Noroeste de Belo Horizonte, de 2006 a 2008.

Nota-se que o local mais trabalhado pelo controle químico vetorial foi o peridomicílio, ao mesmo tempo em que a borrifação do intradomicílio não foi aceita por muitos proprietários. Este fato demonstra que o controle químico vetorial é mais realizado no local onde o flebotomíneo L. longipalpis é geralmente mais encontrado, de acordo com Dias et al. (2003), Souza et al. (2004) e Silva et al. (2007).

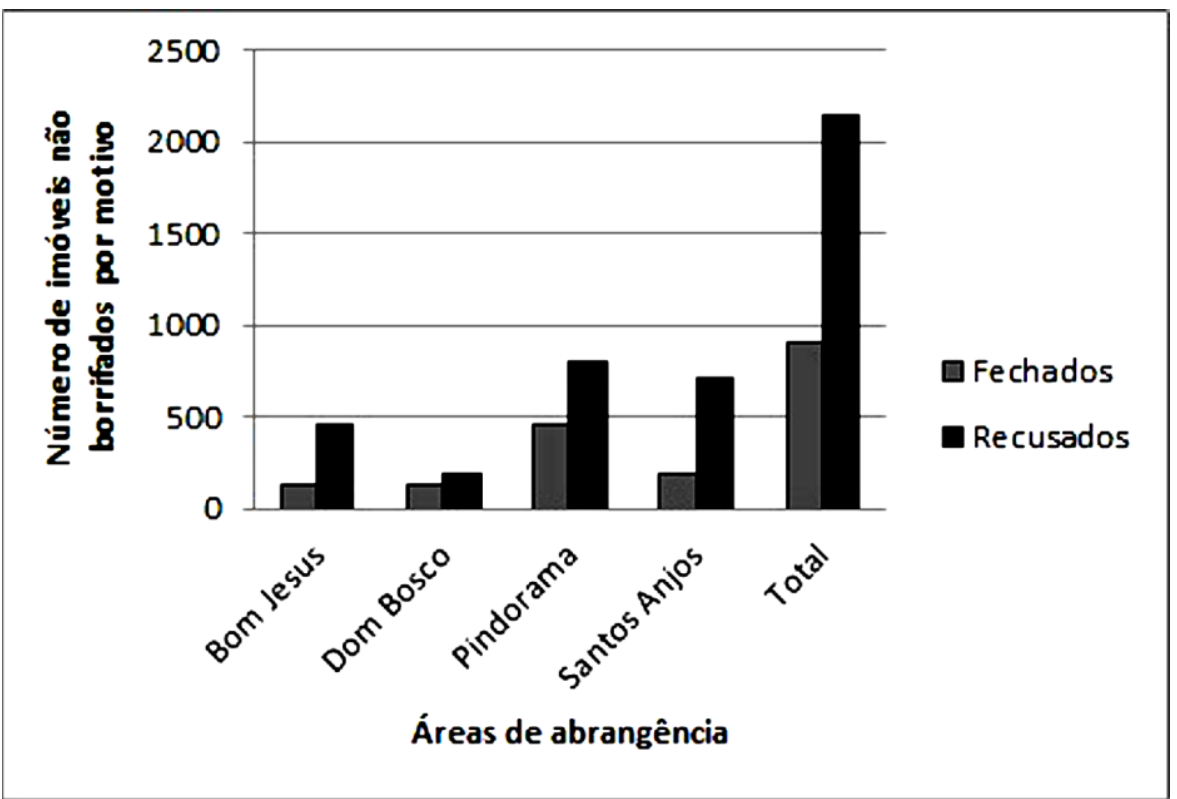

Figura 3. Número de imóveis não borrifados de acordo com o motivo, em quatro áreas de abrangência da Regional Noroeste de Belo Horizonte, de 2006 a 2008. 
Observa-se que o principal motivo para a não realização do controle químico vetorial nos imóveis, no período e na área de estudo, foi a recusa dos seus proprietários. Este fato confirma a constatação de Camargo-Neves (2005), Tauil (2006) e Silva et al. (2007), os quais sugeriram a recusa da população como uma das dificuldades de implementação do controle químico vetorial no Programa de Controle da Leishmaniose Visceral. Tal observação é preocupante, pois, mesmo que o proprietário realize apenas o manejo ambiental, prevenindo a reprodução do inseto vetor em sua residência, sem a proteção do controle químico vetorial, o imóvel fica desprotegido contra o aparecimento do flebotomíneo adulto advindo de outros locais, podendo, inclusive, oferecer abrigo a este inseto.

No período e na área de estudo, foram notificados e confirmados 31 casos humanos de leishmaniose visceral, sendo $15(55,55 \%) \mathrm{em}$ 2006 , sete $(25,93 \%)$ em 2007 e nove $(18,52 \%)$ em 2008.

As áreas de abrangência do Bom Jesus, Pindorama e Santos Anjos foram as que apresentaram queda dos casos humanos de leishmaniose visceral. Este fato pode ser explicado, entre outras razões, pelo elevado número de imóveis borrifados nestas regiões. Importante ressaltar que os proprietários destas regiões apresentaram boa aceitação do controle químico vetorial no exterior e no interior dos domicílios, conferindo proteção integral do imóvel contra o flebotomíneo L. longipalpis. A realização do controle químico vetorial no interior das residências é de fundamental relevância no combate à leishmaniose visceral, pois o intradomicílio se mostrou um local onde o flebotomíneo já se encontra plenamente adaptado, conforme mostrado por Monteiro et al. (2005), Barata et al. (2005) e Resende et al. (2006), aumentando os riscos de contato com as pessoas e de transmissão da doença.

A área de abrangência do Dom Bosco apresentou um grande aumento do número de casos humanos da doença. Tal fato se mostrou surpreendente, dada a semelhante aceitação do controle químico em todas as áreas de abrangência do estudo, no período observado.
Do total de 33.579 endereços visitados para controle químico vetorial, foi possível georreferenciar 13.636 (40,60\%) localidades. As demais consistiam de prédios de apartamentos ou barracões anexos no mesmo lote, considerados individualmente como residência pelo banco de dados utilizado, o que diminuiu o número de pontos georreferenciados nos mapas. Dos 31 casos humanos de leishmaniose visceral ocorridos no período e na área de estudo, foi possível o georreferenciamento de 27 (87\%).

As quatro áreas de abrangência do estudo possuem um total de 567 quarteirões. Destes, $453(79,89 \%)$ apresentaram informação completa e disponível sobre os trabalhos de borrifação no período estudado. O restante dos quarteirões $(20,1 \%)$ provavelmente não se encontrava em áreas contempladas pelo controle químico vetorial, ou ocorreu possível perda do boletim antes de sua digitação. O perfil de recusas da população ao controle químico e os casos humanos de leishmaniose visceral, no período e nas áreas de estudo, encontram-se nas Fig. 4 e 5.

A classificação dos quarteirões baseada na média da pontuação de suas residências mostrou a maior predominância de quarteirões com maioria de imóveis onde o proprietário apresentou recusa da borrifação interna (quarteirões amarelos) e recusa total da borrifação (quarteirões vermelhos), demonstrando a baixa aceitação do controle químico vetorial pela população da área estudada. Este fato comprova, novamente, as afirmações de Camargo-Neves (2005), Tauil (2006) e Silva et al. (2007), ao citarem as recusas por parte da população como uma das dificuldades para a realização do Programa de Controle da Leishmaniose Visceral.

Observa-se, nas Fig. 4 e 5, a presença de casos humanos de leishmaniose visceral em todas as áreas estudadas. Tal fato evidencia a plena urbanização da leishmaniose visceral nos grandes centros urbanos, conforme descrito por Marzochi et al. (1985), Monteiro et al. (1994), Bevilacqua et al. (2001), Barata et al. (2005), Rangel e Vilela (2008) e Borges et al. (2008). 


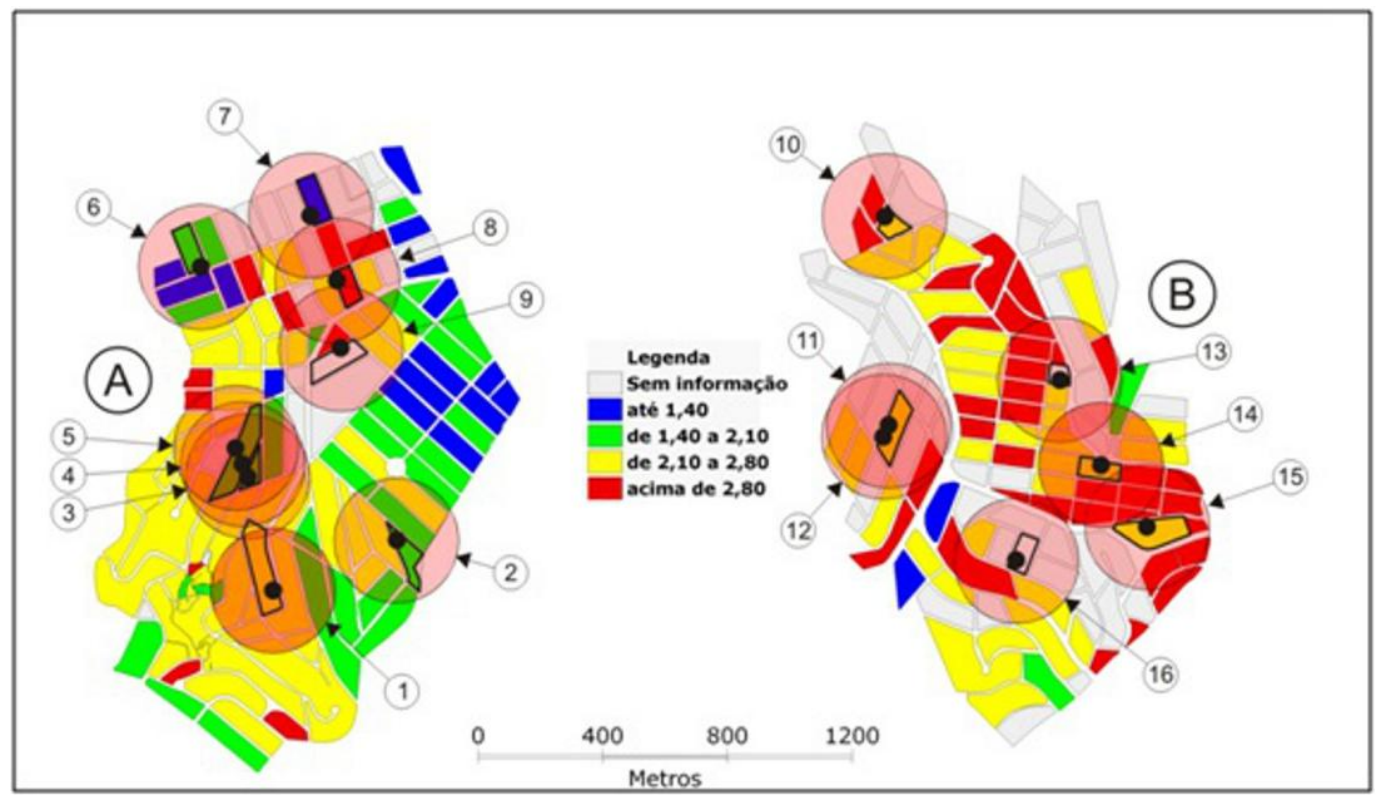

Figura 4. Casos humanos de leishmaniose visceral e escore de recusas nas áreas de abrangência Pindorama (A) e Dom Bosco (B), da Regional Noroeste de Belo Horizonte, de 2006 a 2008.

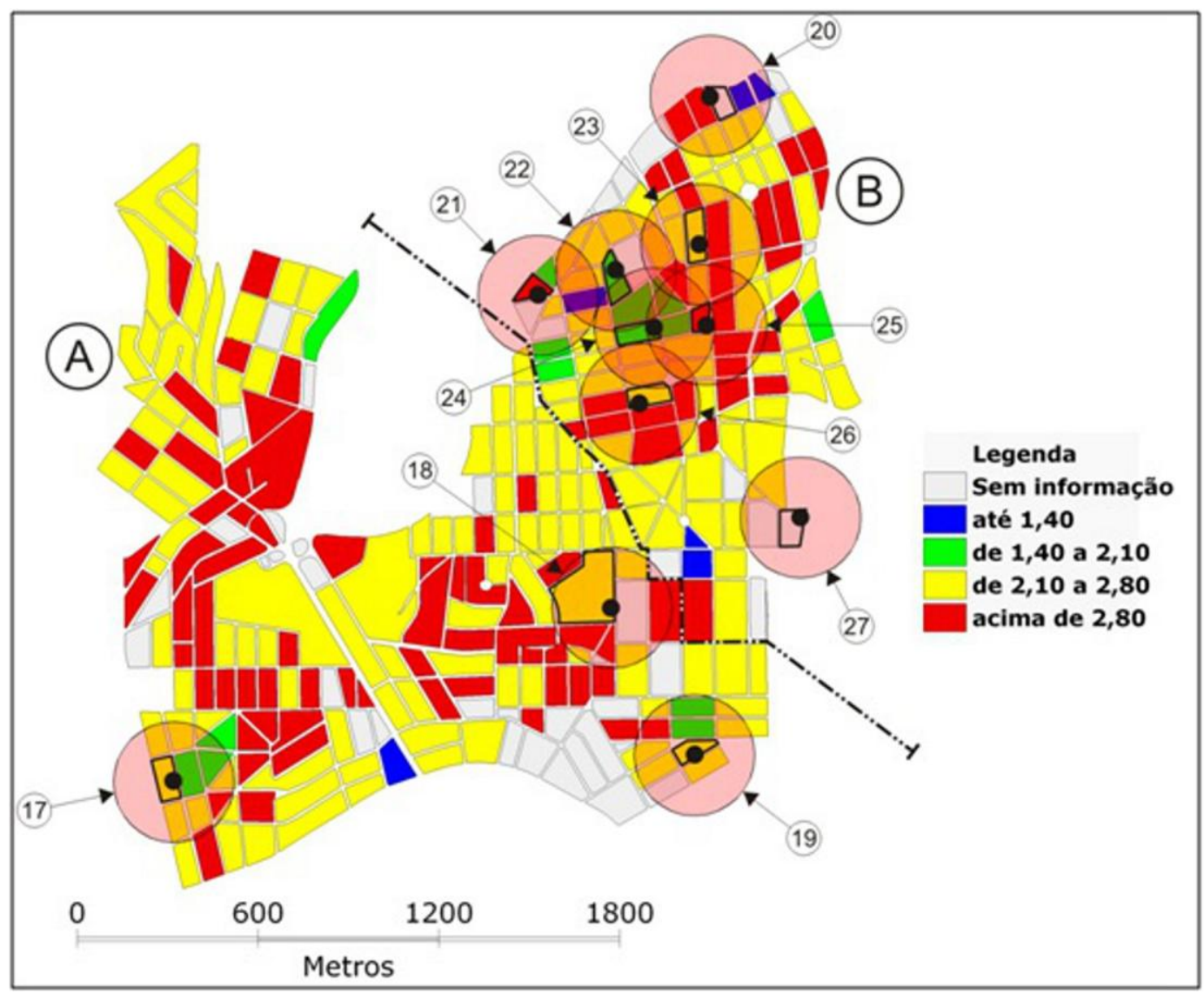

Figura 5. Casos humanos de leishmaniose visceral e escore de recusas nas áreas de abrangência Santos Anjos (A) e Bom Jesus (B), da Regional Noroeste de Belo Horizonte, de 2006 a 2008. 
Importante notar que, dos 27 casos humanos da doença, mais da metade $(51,85 \%)$ se encontra em quarteirões onde o controle químico vetorial não obteve boa aceitação pelos proprietários (quarteirões em amarelo e vermelho). A falta da borrifação no interior do domicílio possibilita o maior contato do inseto vetor da leishmaniose visceral com os moradores do imóvel, principalmente no período crepuscular, quando o inseto se alimenta mais, como ressaltaram Barata et al. (2005), aumentando, assim, o risco de transmissão da doença.

Alguns casos humanos, contudo, foram localizados em quarteirões onde a maior parte das residências apresentou baixo escore de risco, com aceitação total da borrifação (quarteirões em azul) ou borrifação apenas do intradomicílio (quarteirões em verde). Estes fatos podem ser explicados, provavelmente, pela borrifação de residências e arredores imediatamente após a notificação de casos humanos de leishmaniose visceral.

A diferença entre o perfil de recusas dos quarteirões contidos em uma área de 200 metros ao redor de um caso humano de leishmaniose visceral e o mesmo perfil dos quarteirões fora desta área foi significativa em $11(40,74 \%)$ dos 27 casos humanos da doença.

Em uma análise mais detalhada, verificou-se a relação dos casos humanos da doença de forma individual com a borrifação dos seus respectivos logradouros. Do total de 31 casos humanos de leishmaniose visceral no período e na área de estudo, entretanto, 12 ocorreram anteriormente à borrifação anual dos respectivos logradouros. Nestes casos, consequentemente, a recusa do proprietário em permitir a borrifação de seu imóvel não poderia ser responsabilizada como causa do surgimento da doença, pois o agravo ocorreu antes da ação de controle.

Portanto, do total de 11 casos humanos de leishmaniose visceral cuja análise estatística do perfil de recusas foi significativa, sete ocorreram após a borrifação dos logradouros. Ou seja, por se localizarem em uma região onde o controle químico vetorial foi mais recusado 200 metros próximos a eles do que fora desta área, estes sete casos humanos da doença podem ter ocorrido, entre outras causas, pela recusa individual destes proprietários em permitir a borrifação de seus imóveis.
Ao se considerarem os resultados desta pesquisa, deve-se lembrar de que a leishmaniose visceral é uma doença de ciclo biológico e de fatores epidemiológicos complexos. Consequentemente, o Programa de Controle da Leishmaniose Visceral se baseia não apenas no controle químico vetorial, mas também na rápida detecção e eliminação dos cães soropositivos, no tratamento dos casos humanos e nas atividades em educação em saúde, de forma integrada e continuada, conforme ressaltado por Costa et al. (2001), Gontijo e Melo (2004) e Maia-Elkhoury (2008).

Para se certificar da variação do número de casos humanos de leishmaniose visceral, seria necessária a análise de outros métodos de controle da doença além do controle químico com inseticida. $\mathrm{O}$ aparecimento dos casos humanos da doença resulta de mais limitações à realização do Programa de Controle da Leishmaniose Visceral do que apenas a recusa da população em permitir o controle químico vetorial em suas residências, ou a recusa desta população em permitir a eutanásia dos cães soropositivos, ou ainda a alta taxa de reposição destes animais após esta medida, entre outras limitações. O baixo número de casos humanos para análise e a impossibilidade do pesquisador de estar presente no momento das borrifações limitou o controle desta pesquisa sobre tais fatores.

O estudo da associação entre os casos humanos de leishmaniose visceral e a recusa desta população em permitir a eutanásia dos cães soropositivos se faz necessário, pois a prevalência da doença no cão precede a prevalência da doença no homem, conforme demonstraram Oliveira et al. (2001) e Margonari et al. (2006). Espera-se que os resultados deste trabalho tragam um melhor conhecimento de como a população responde a este importante método de controle (que tanto impacta em suas vidas cotidianas) para que sua metodologia seja aprimorada objetivando-se a maior eficácia possível no combate à leishmaniose visceral.

Verificou-se, na prática do serviço de controle químico vetorial, que as recusas à borrifação frequentemente ocorrem pelo desconhecimento dos moradores em relação à leishmaniose visceral. Muitos agentes de combate a endemias têm consciência da importância do controle 
químico vetorial no combate à leishmaniose visceral e, consequentemente, possuem a preocupação de repassar ao proprietário do domicílio o maior número possível de informações e esclarecimentos sobre a doença, a fim de convencê-lo a permitir a borrifação integral de seu imóvel. Para muitos agentes, "gastar mais tempo", durante o agendamento da borrifação, apresentando explicações sobre a leishmaniose visceral ao morador, por meio de panfletos informativos, significa, na prática, a melhor solução para evitar uma recusa, muitas vezes precipitada, e uma aceitação maior do controle químico vetorial, melhorando o controle da enfermidade na área.

Como ressaltaram Tauil (2006) e Borges et al. (2008), o investimento em programas de educação em saúde e avaliação destes é fundamental em qualquer programa de controle de doença que envolva a participação popular. Estes programas, além de menos dispendiosos, apresentam resultados eficazes e duradouros no combate à leishmaniose visceral, conforme enfatizado por Magalhães et al. (2009).

\section{REFERÊNCIAS}

ALEXANDER, B.; YOUNG, D.G. Dispersal of phlebotomine sand flies (diptera: psychodidae) in a colombian focus of Leishmania (viannia) braziliensis. Mem. Inst. Oswaldo Cruz, v.87, p.397-403, 1992.

BARATA, R.A.; SILVA, J.C.F.; MAYRINK, W. et al. Aspectos da ecologia e do comportamento de flebotomíneos em área endêmica de leishmaniose visceral, Minas Gerais. Rev. Soc. Bras. Med. Trop., v.38, p.421-425, 2005.

BEVILACQUA, P.D.; PAIXÃO, H.H.; MODENA, C.M. et al. Urbanização da leishmaniose visceral em Belo Horizonte, Arq. Bras. Med. Vet. Zootec. v.53, p.1-8, 2001.

BORGES, B.K.A.; SILVA, J.A.; HADDAD, J.P.A. et al. Avaliação do nível de conhecimento e de atitudes preventivas da população sobre a leishmaniose visceral em Belo Horizonte, Minas Gerais, Brasil. Cad. Saúde Pública, v.24, p.777-784, 2008.

CAMARGO-NEVES, V.L.F. Utilização de coleiras impregnadas com deltametrina a $4 \%$ para o controle da leishmaniose visceral americana. Resultados preliminares de um estudo conduzido no Estado de São Paulo, Brasil. In: Informe Final de la Reunión de Expertos OPS/OMS sobre Leishmaniasis Visceral en las Américas. Rio de Janeiro: Organización Panamericana de la Salud, 2006. p.99-103.
COSTA, C.H.N.; VIEIRA, J.B.F. Changes in the control program of visceral leishmaniasis in Brazil. Rev. Soc. Bras. Med. Trop., v.34, p.223-228, 2001.

DESJEUX, P. The increase in risk factors for leishmaniasis worldwide. Trans. Roy. Soc. Trop. Med. Hyg. v.95, p.239-243, 2001.

DIAS, J.C.P. Problemas e possibilidades de participação comunitária no controle das grandes endemias no Brasil. Cad. Saúde Pública, v.14, supl. 2, p.19-37, 1998

DIAS, F.O.P.; LOROSA, E.S.; REBELO, J.M.M. Fonte alimentar sanguínea e a peridomiciliação de Lutzomyia longipalpis (Lutz \& Neiva, 1912) (Psychodidae, Phlebotominae). Cad. Saúde Pública, v.19, p.1373-1380, 2003.

GONTIJO, C.M.F., MELO, M.N. Leishmaniose Visceral no Brasil: quadro atual, desafios e perspectivas. Rev. Bras. Epidemiol., v.7, p.338-349, 2004.

Instituto Brasileiro de Geografia e Estatística, 2007. Censo populacional de 2000. Disponível em: <www.ibge.gov.br/censo2000〉. Acessado em: 28/10/09.

MAGALHÃES, D.F; SILVA, J.A.; HADDAD, J.P.A. et al. Informação sobre leishmaniose visceral por escolares aos seus familiares: uma abordagem sustentável para o controle da doença. Cad. Saúde Pública, v.25, p.1642-1646, 2009.

MAIA-ELKHOURY, A.N.S; ALVES, W.A.; SOUZA-GOMES, M.L. et al. Visceral leishmaniasis in Brazil: trends and challenges. Cad. Saúde Pública, v.24, p.2941-2947, 2008.

MARGONARI, C.; FREITAS, C.R.; RIBEIRO, R.C. Epidemiology of visceral leishmaniasis through spatial analysis, in Belo Horizonte municipality, state of Minas Gerais, Brazil. Mem Inst Oswaldo Cruz, v.101, p.31-38, 2006.

MARZOCHI, M.C.A.; SABROZA, P.C.; TOLEDO, L.M. et al. Leishmaniose visceral na cidade do Rio de Janeiro, Brasil. Cad. Saúde Pública, v.1, p.432-446, 1985.

MONTEIRO, E.M; SILVA, J.C.F.; COSTA, R.T. et al. Leishmaniose visceral: estudo de flebotomíneos e infecção canina em Montes Claros, Minas Gerais. Rev. Soc. Bras. Med. Trop., v.38, p.147-152, 2005.

MONTEIRO, O.S.; Lacerda, M.M.; Arias, J.R. Controle da leishmaniose visceral no Brasil. Rev. Soc. Bras. Med. Trop., v.27, p.67-72, 1994.

OLIVEIRA, C.D.L.; ASSUNÇÃO, R.M.; REIS, I.A. Spatial distribution of human and canine visceral leishmaniasis in Belo Horizonte, Minas Gerais State, Brasil, 1994-1997. Cad. Saúde Pública, v.17, p.12311239,2001 
RANGEL， E.F.; VILELA, M.L. Lutzomyia longipalpis (Diptera, Psychodidae, Phlebotominae) and urbanization of visceral leishmaniasis in Brazil. Cad. Saúde Pública, v.24, p.2948-2952, 2008.

RESENDE, M.C.; CAMARGO, M.C.V.; VIEIRA, J.R.M. et al. Seasonal variation of Lutzomyia longipalpis in Belo Horizonte, State of Minas Gerais. Rev. Soc. Bras. Med. Trop. v.39, p.51-55, 2006.

SAMPAIO, I.B.M. Estatística aplicada à experimentação animal. Belo Horizonte: Fundação de Estudo e Pesquisa em Medicina Veterinária e Zootecnia, 1998. 221p.

SILVA, E.A.; ANDREOTTI, R.; RONER, M.R. et al. Comportamento de Lutzomyia longipalpis, vetor principal da leishmaniose visceral americana, em Campo Grande, Estado do Mato Grosso do Sul. Rev. Soc. Bras. Med. Trop., v.40, p.420-425, 2007.
SOUZA, C.M; PESSANHA, J.E.; BARATA, R.A. et al. Study on phlebotomine sand fly (Diptera: Psychodidae) fauna in Belo Horizonte, State of Minas Gerais, Brazil. Mem Inst. Oswaldo Cruz, v.99, p.795803, 2004.

TAUIL, P.L. Perspectivas de controle de doenças transmitidas por vetores no Brasil. Rev. Soc. Bras. Med. Trop., v.39, p.275-277, 2006.

TERRAVIEW, Software versão 3.2. Instituto Nacional de Pesquisas Espaciais. Brasília - DF: Ministério da Ciência e Tecnologia, 2008. 